\title{
Does flagship species tourism benefit conservation? A case study of the golden snub-nosed monkey in Shennongjia National Nature Reserve
}

\author{
XIANG ZuoFu ${ }^{1,2}$, YU Yang $^{1}$, YANG Mei ${ }^{4}$, YANG Jing Yuan ${ }^{3}$, NIAO Ming Yao ${ }^{3} \&$ LI Ming $^{2 *}$ \\ ${ }^{1}$ College of Life Science and Technology, Central South University of Forestry \& Technology, Changsha 410004, China; \\ ${ }^{2}$ Key Laboratory of Animal Ecology and Conservation Biology, Institute of Zoology, Chinese Academy of Sciences, Beijing 100101, China; \\ ${ }^{3}$ Administration Bureau of Shennongjia National Nature Reserve, Shennongjia Forest District, Shennongjia 442411, China; \\ ${ }^{4}$ College of Tourism, Central South University of Forestry \& Technology, Changsha 410004, China
}

Received February 28, 2011; accepted May 17, 2011

\begin{abstract}
Tourism has been widely used as a conservation strategy that directly compensates local people or management authorities, thereby contributing to development and creating incentives to preserve the landscape. Reserves or parks that are inhabited by flagship species may be able to generate more revenue through tourism than those without such species because flagship species have great potential for raising funds and creating publicity for conservation goals. In this paper, we examine flagship species tourism focused on observing the golden snub-nosed monkey (Rhinopithecus roxellana) in Shennongjia National Nature Reserve (SNNR). After the program was launched in 2006, both the number of tourists and amount of revenue received by SNNR increased as the general trends of tourism revenue in the country also increased. As a result, SNNR significantly increased reinvestment in tourism and conservation infrastructure. Furthermore, after senior politicians visited the golden snub-nosed monkey, they abruptly changed their attitudes toward biological conservation, as indicated by an increase in both regular and additional funding for the species conservation. We conclude that flagship species tourism may not only generate revenue for conservation and management but also can improve officials' attitudes toward preserving biodiversity. However, it is important to ensure the continued safety and sustainability of such programs, from both the human and animal perspective, and we suggest stricter measures are introduced to reduce the risk of aerosol disease transmission from tourists to the monkeys.
\end{abstract}

flagship species, tourism, Shennongjia Nature Reserve, Rhinopithecus roxellana

Citation: Xiang Z F, Yu Y, Yang M, et al. Does flagship species tourism benefit conservation? A case study of the golden snub-nosed monkey in Shennongjia National Nature Reserve. Chinese Sci Bull, 2011, 56: 2553-2558, doi: 10.1007/s11434-011-4613-x

Conservation means different things to different people, and these meanings have shifted through time as alternative interpretations have passed in and out of favor. To some, conservation is about the preservation of wilderness; areas untouched by the influence of humans. To others, it is about the protection of resources required to ensure a sustainable future for life on Earth. There are others still who feel it is about preventing species' extinction. These distinct interpretations of the role of conservation reflect different ways in which value can be placed on the natural environment,

*Corresponding author (email: lim@ioz.ac.cn) either as a resource to be exploited now or in the future, or as something having intrinsic value [1]. The costs of protecting these natural environments tend to be incurred by people living in or close to them; local stakeholders can become severely restricted in how they may develop their communities. Tourism has been touted as a means through which local people and management authorities can be compensated for their losses, thereby promoting sustainable development and creating incentives for conservation.

It has been argued that reserves or parks that are inhabited by flagship species can generate more revenue through tourism than those without them because flagship species 
may help raise funds and increase public awareness of conservation aims. First, tourism can directly support conservation by generating revenue to pay for management activities. These monies come from fees charged for entry to the reserve or park, or for access to a particular species [2]. Second, revenue can be reinvested in conservation-related activities, such as building additional infrastructure or moving local people out of the protected area. Third, tourism focused on flagship species has the potential to improve the attitude of local residents and senior government officials toward conservation goals.

The golden snub-nosed monkey (Rhinopithecus roxellana), also known as the Sichuan snub-nosed monkey, is categorized as Endangered on the IUCN Red List (http://www. iucnredlist.org). It is endemic to China and occurs in the provinces of Sichuan, Gansu, Shanxi, and Hubei. It is an arboreal forest dweller found in temperate broadleaf and coniferous forest at elevations between 1500 and $3500 \mathrm{~m}$ above sea level. It has reddish-gold hair and a bluish face with a small, upturned nose. Adult males have lappets at the sides of their mouths whose function is currently unknown. Like the panda, the golden snub-nosed monkey is considered as a national treasure of China. Because agricultural expansion has resulted in widespread deforestation, the species' distribution has contracted over the last 400 years to now include only isolated, mountainous regions [3]. It is very difficult to view the golden snub-nosed monkey in its natural environment for several reasons. The steep slopes and deep gorges of the monkeys' habitat are difficult to traverse. Some mountain paths are closed for four months of the year because of heavy snowfalls. The visibility of the animals in the forest is very low, partly because they are extremely shy toward people because of a long history of hunting. These factors, plus the fact that very few individuals are kept in captivity, make the golden snub-nosed monkey a good candidate for flagship species tourism.

In this paper, we examine flagship tourism promoting the golden snub-nosed monkey in Shennongjia National Nature Reserve, China. We analyzed its impact on biodiversity conservation and predicted that the number of tourists and amount of revenue would increase, and the officials' attitudes toward biological conservation would also change after flagship tourism was launched. We also predicted that as revenues increased, reinvestment of funds in infrastructure would also increase.

\section{Materials and methods}

\subsection{Study sites}

We conducted the study at the Shennongjia National Nature Reserve (SNNR). SNNR is located in the northwestern region of Hubei Province, Central China. SNNR was established in 1986 under the authority of the Chinese government. In 1990, it became a member of UNESCO's Interna- tional Network of Biosphere Reserves.

SNNR is famous within China for its unique geographic location, complex terrain and high biodiversity [4-6]. The faunal composition of SNNR is highly diverse, featuring many endemic animals with notable megafauna including leopards, bears, wild boars and golden snub-nosed monkeys [7].

\subsection{Flagship species tourism in SNNR}

There are three subpopulations and eight groups with $>1200$ individuals of $R$. roxellana maintained in SNNR. These subpopulations are Jinhouling (two groups), Dalongtan (three groups) and Qianjiaping (three groups). To facilitate ecotourism focused on golden snub-nosed monkeys, a small group (about 60 individuals) of Dalongtan subpopulation was successfully habituated to humans by the administrative bureau of SNNR in January, 2006. In the beginning, the monkeys were regularly provided with food at a specific remote location while live videos were transmitted to the tourism center. Since 2007, tourists with permission from the administrative bureau of SNNR could observe the golden snub-nosed monkey directly after the monkeys were fully-habituated.

During golden snub-nosed monkey observation, tourists are restricted to observe the monkey along a tourism road from about $20-30 \mathrm{~m}$ away at two fixed visiting times (09:00-10:00 and 16:00-17:00). The monkeys are free to roam in their habitat and provisioned three times every day. Food consists of apples, peaches, carrots, oranges, peanuts, as well as foods, such as lichens, pine cones, cloud grass, and deciduous leaves, from their natural environment. However, there are instances in which tourists have been allowed to become much closer to the monkeys, in close enough contact to take photographs with them.

There is a special management office that charges tourists in SNNR. It is responsible for the monkeys' provisioning and purchases foods such as lichen, certain deciduous leaves and fruit. They also monitor diseases and behavior to make sure the monkeys stay in good health. However, few measures have been taken to prevent disease transmission between tourists and monkeys.

\subsection{Data collection and analysis}

Data on yearly tourist visits and revenues from 2000 to 2010 were collected from the ticket office in SNNR. Data on reinvestment in tourism infrastructure (such as support for mass tourism and road building) and conservation activities (such as building a protection station after moving local people out of SNNR) were collected from the administrative bureau of SNNR.

To test the hypothesis that flagship tourism increases the number of tourists and overall revenue, we used the MannWhitney $U$ test [8] to test for differences in yearly mean number of tourists and revenues before and after flagship 
tourism was launched. The Mann-Whitney U test was also used to test for differences in reinvestment in tourism infrastructure and conservation activities before and after flagship species tourism was launched. To determine if the flagship species changed government officials' attitudes toward biodiversity conservation, we compared the annual mean additional investment from senior government agencies in conservation before and after flagship species tourism was launched.

\section{Results}

\subsection{Tourist numbers and revenues in 2000-2010}

Tourist numbers and revenues for SNNR are presented in Figure 1. Number of tourists and revenues significantly increased after the onset of flagship species tourism. In 2005, there were 125000 tourists and 1585000 USD in revenues was collected. However, by 2010 , these had reached about 236000 people and 3390000 USD. The annual mean numbers of tourists during 2006-2010 were significantly higher than those of 2000-2005 (Mann-Whitney U test, $U_{0.05,(2), 6,5}=$ $0.00, P<0.01)$. The annual mean revenues in 2006-2010 were significantly higher than those in 2000-2005 (MannWhitney U test, $\left.U_{0.05,(2), 6,5}=0.00, P<0.01\right)$.

\subsection{Reinvestment in tourism and conservation infrastructure in 2000-2010}

Changes in investment in tourism infrastructure, such as road building, and conservation activities, such as building a protection station after moving local people out of SNNR, are presented in Figure 2. SNNR significantly increased investment in tourism infrastructure after 2005 (MannWhitney U test, $\left.U_{0.05,(2), 6,5}=0.00, P<0.01\right)$. For example, in 2005 , only 75758 USD was invested in tourism infrastructure while in 2006, it reached 378788 USD. However, it reached 4545455 USD of investment in tourism infrastructure in 2010. After flagship species tourism was begun, SNNR significantly increased investment in conservation activities (Mann-Whitney U test, $U_{0.05,(2), 6,5}=1.00, P<0.05$ ). For example, in 2005, only 151515 USD was used in building a protection station; however, it reached 357576 USD in 2010. The administrative bureau of SNNR gradually moved

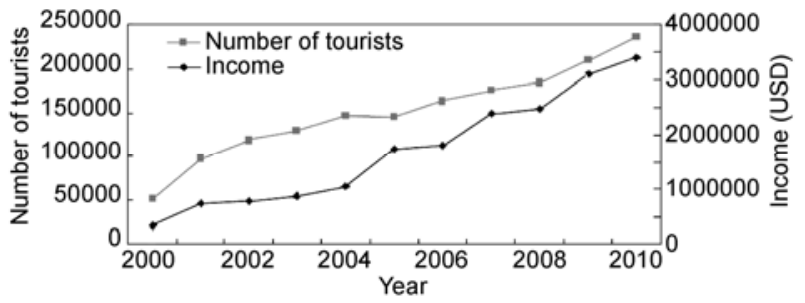

Figure 1 Tourist numbers and revenues during 2000-2010 in Shennongjia National Nature Reserve, China.
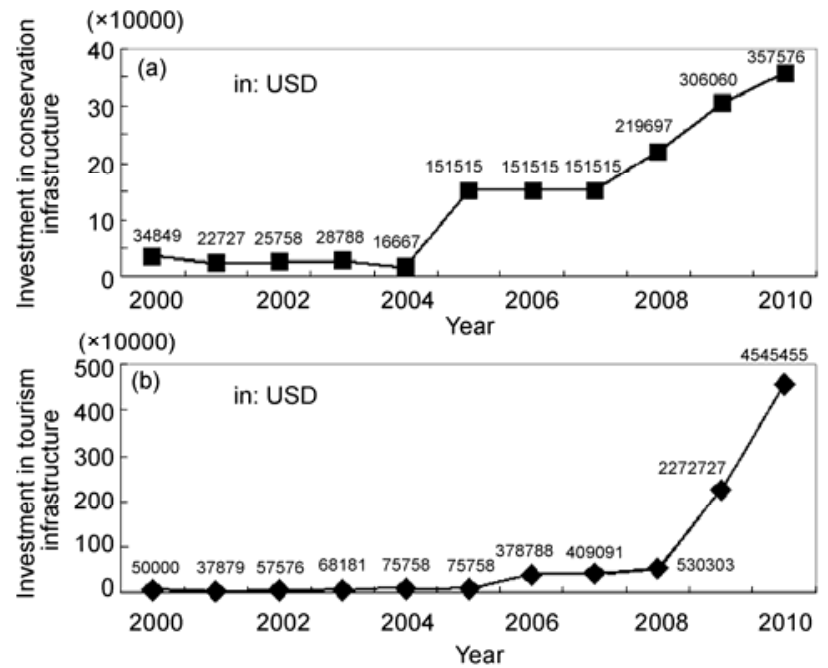

Figure 2 Reinvestment in conservation activities (a) and tourism infrastructure (b) during 2000-2010 in Shennongjia National Nature Reserve, China.

local people out of SNNR since 2000 when the Chinese government began to implement the policy of conceding the land to forestry. The number of households and people that moved out of SNNR and the financial compensation for these people during 2000-2010 is shown in Table 1. There was no significant difference in the number of households or villagers moving out of SNNR, or the amount of compensation for these people before and after flagship tourism was begun (Mann-Whitney U test, householder: $U_{0.05,(2), 6,5}=$ 4.50, $P>0.05$; population: $U_{0.05,(2), 6.5}=6.50, P>0.05$; compensation: $\left.U_{0.05,(2), 6,5}=6.50, P>0.05\right)$.

\subsection{Tourist numbers and revenues from observation of the golden snub-nosed monkey}

To reduce negative impacts on the golden snub-nosed

Table 1 Number of households and overall population relocated from the Shennongjia National Nature Reserve and amount of compensation given during 2000-2010

\begin{tabular}{cccc}
\hline Year & $\begin{array}{c}\text { Households } \\
\text { (families) }\end{array}$ & $\begin{array}{c}\text { Population } \\
\text { (individuals) }\end{array}$ & Compensation (USD) \\
\hline 2000 & 19 & 36 & 28030 \\
2001 & 22 & 45 & 34091 \\
2002 & 37 & 63 & 47727 \\
2003 & 13 & 31 & 23485 \\
2004 & 11 & 33 & 25000 \\
2005 & 8 & 24 & 18182 \\
2006 & 8 & 32 & 24242 \\
2007 & 13 & 29 & 21970 \\
2008 & 9 & 33 & 25000 \\
2009 & 8 & 28 & 21212 \\
2010 & 7 & 21 & 15909 \\
Total & 155 & 375 & 284848 \\
\hline
\end{tabular}


monkey, the number of tourists allowed to observe the monkeys was controlled. Therefore, revenues from direct observation of the golden snub-nosed monkey were small because it is difficult for tourists to get permission from the authorities at SNNR. Number of tourists and revenues from observing golden snub-nosed monkeys are presented in Table 2. Only 2336 tourists closely observed the golden snubnosed monkey during 2006-2010. Furthermore, during the pig flu outbreak in 2009, tourists were prohibited from observing the monkeys. As a result, revenues were negligible compared with those from mass tourism in the rest of the reserve.

After a group of politicians, from provincial to state level, visited the golden snub-nosed monkey, the attitudes in government toward biological conservation immediately changed. Additional investment in biodiversity conservation from senior government (Figure 3) considerably increased. For example, in 2005, only 60600 USD was put toward biodiversity conservation; however, in 2010, it was increased to 484848 USD. Importantly, SNNR gets regular funding (about 348485 USD every year) from the Department of Science and Technology and the Department of Finance, Hubei Province. Furthermore, an additional funding of about 5 million USD from the Department of Development and Reform Commission of Hubei was allocated to conservation. Annual investments in biodiversity conservation during 2006-2010 are significantly higher than those during 2000-2005 (Mann-Whitney U test, $U_{0.05,(2), 6,5}=0.00, P<$ $0.01)$.

Table 2 Number of tourists and revenues collected from observation of the golden snub-nosed monkey (Rhinopithecus roxellana) during 2006-2010

\begin{tabular}{lcc}
\hline Year & Tourists & Revenues (USD) \\
\hline 2006 & 50 & 1299 \\
2007 & 310 & 7176 \\
2008 & 335 & 9611 \\
2009 & $80^{\text {a) }}$ & 447 \\
2010 & 1561 & 21656 \\
Total & 2336 & 40189 \\
\hline
\end{tabular}

a) Because of a pig flu outbreak, tourists were prohibited from observing the monkeys.

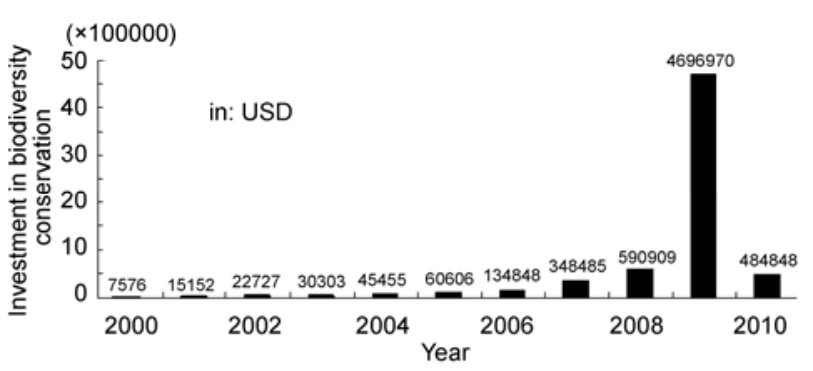

Figure 3 Additional investment in biodiversity conservation from senior government during 2000-2010 in Shennongjia National Nature Reserve, China.

\section{Discussion}

\subsection{Flagship species tourism raised funds for conservation}

Tourism at Shennongiia raises a very substantial sum of money for the SNNR authority. It doubled revenues in 2010 from the 2005 levels as the general trends of tourism revenue in the country also increased (http://www.stats.gov. $\mathrm{cn} / \mathrm{tjgb} /)$. However, direct revenues from golden snub-nosed monkey observation only raises 8000 USD per year during 2006-2010 because the administrative bureau was concerned about the potential negative impact on the monkey and therefore strictly controlled the number of tourists observing monkeys. However, after officials of provincial government visited the monkeys, they abruptly changed their attitudes toward biodiversity and promised to transfer regular funds toward species conservation in SNNR. The SNNR gets regular funding (about 348485 USD every year) from the Department of Science and Technology and the Department of Finance, Hubei Province. Apart from regular funding, SNNR received an extra 5 million USD from the Department of Development and Reform Commission of Hubei in 2009. Increasing revenues also justified reinvestment in tourism and conservation infrastructure. Therefore, tourism in SNNR appears to benefit biodiversity conservation. There are many other instances of flagship species tourism since the demand for ecotourism is predominantly focused on charismatic megafauna [9]. Examples include Magellanic penguins Spheniscus magellanicus [10,11], gorillas Gorilla gorilla gorilla [12,13], brown bears Ursus arctos [14], Komodo dragons Varanus komodoensis [15], and black rhinos Diceros bicornis [16].

\subsection{Challenges for tourism and flagship species}

Wildlife ecotourism attractions can be useful strategies for biodiversity conservation because they have the potential to generate funds and public support that will benefit protected areas in which endangered species reside. Species that can attract such attention are arguably conservation flagships. Whilst single-species conservation may no longer be appropriate in the landscape era [17], single-species marketing for strategic conservation objectives is entirely appropriate given the need for attractions with which the public can identify.

Since most flagship species rely on protected areas that conserve wider biodiversity, it will generally be the case that the preservation of biodiversity in general will benefit from the funds generated by flagship species. In the case of the present study, after flagship species tourism was introduced, both direct revenues from tourism and indirect funding of conservation initiatives from senior government increased. In this way, flagship species tourism may have helped SNNR to succeed where many other parks in China have not. However, the beautiful scenery of SNNR may also play a key role in the amount of tourism, because 
golden snub-nosed monkeys also occur in other nature reserves. The key difference is that SNNR is the first destination where wild golden snub-nosed monkeys are habituated to tourists in China. In the future, SNNR may face difficulties if groups of golden snub-nosed monkeys are habituated for ecotourism purposes at other nature reserves in China. Flagship species tourism at SNNR may no longer be sustainable at that point.

\subsection{Costs of tourism for biodiversity conservation}

The most obvious impacts that ecotourism can have on the environment are physical degradations caused by erosion, infrastructure construction and waste disposal [18]. Numerous examples of these impacts can be found in the literature, such as the effects of trampling on vegetation in various parks [19-22], the impact of solid waste disposal in the Maldives and Nepal [23], and the impacts of tourist vehicles on protected areas such as the Masai Mara game reserve in Kenya [24]. As well as affecting the physical environment, ecotourism can have direct impacts on resident species, including those of conservation concern. A major concern is that diseases could be transmitted from humans to wild animals [25]. This is a particularly concern for great apes and monkeys, which are vulnerable to many human diseases [26-29]. However, although hiring a disease monitor was considered, no measures have been taken to prevent the transfer of disease from tourists to monkeys. This issue could be addressed with interventions targeting tourists before they are permitted to observe the monkeys. We recommend that the SNNR authority should maintain strict enforcement of rules and regulations on tourist and research visits to the monkeys. Tourists observing the monkeys could be required to wear surgical face masks to reduce the risk of aerosol disease transmission.

Another concern is that habituation for ecotourism can induce both acute and chronic stress in the monkeys. Acute stress during habituation may potentially lead to increased vulnerability to disease, as well as reduced reproductive rates. Chronic stress from interaction with humans may alter the frequency of certain natural behaviors (e.g. fighting and/or socializing). Animals habituated to the presence of tourists may experience increased levels of stress, which could be measured by hormonal analysis $[10,11]$. In the case of choric stress, even when they are no longer acutely stressed, research in mountain gorillas has shown that stress hormone levels remain higher than those pre-exposure [30]. Development and implementation of a research protocol for stress monitoring during ecotourism and strict adherence to regulations may minimize chronic stress.

A final concern is that habituation for ecotourism can result in behavioral changes and social disruption. For example, tourism can affect feeding and ranging behavior as animals attempt to avoid humans [12-14,31-33]. In birds, it has been known to affect nesting behavior [34] and chick survivorship [35]. Further research is needed to understand what, if any, behavioral changes may have been caused by human contact in the golden snub-nosed monkey.

\section{Conclusions and recommendations}

Despite the popularity of tourism as a conservation strategy, little is known about how well tourism performs in practice as a tool for conservation and development. This report has addressed some aspects of this issue, disaggregating some of the key impacts of tourism for biodiversity conservation at SNNR. Generally speaking, the results suggest that tourism has performed well as a conservation strategy in the study area despite some drawbacks. The tourism has delivered measurable economic benefits, improved government attitudes to the conservation, and the funding of some conservation activities. However, there were also considerable problems: first, how the local people or community received the tourism benefits were unclear; second, how the local people or community incurred costs of conservation and tourism were uncertain; third, close human contact brings a threat of disease transmission to the golden snub-nosed monkey. Various interventions could be implemented to remedy these difficulties: first, increasing opportunities for local people to participate in tourism and share tourism benefits; second, introducing stricter measures to reduce the risk of disease transmission from tourists to the monkeys, in particular, during the visit to the golden monkeys, tourists could be required to wear surgical face masks to reduce the risk of aerosol disease transmission; third, golden snubnosed monkey tourism management should be based on sound and objective science, and hence further study on the potential impact of tourism on the focus animal should be encouraged.

We thank the Administration Bureau of Shennongjia National Nature Reserve for their support, and Yao $H, Y u H L$, and Yu P L for field assistance, Alica Krzton for useful suggestions and editing the English in the manuscript, and two anonymous reviewers for useful suggestions that improved the manuscript. This work was supported by the National Natural Science Foundation of China (30870375 and 31071937), the Project of Public Benefit for the Forestry (201104073), and the National Basic Research Program of China (2007CB411600).

1 Hodge I. Environmental Economics. London: Macmillan Press, 1995

2 Walpole M, Goodwin H, Ward K. Pricing policy for tourism in protected areas: Lessons from Komodo National Park, Indonesia. Conserv Biol, 2001, 5: 218-227

3 Li B G, Pan R L, Oxnard C E. Extinction of snub-nosed monkeys in China during the past 400 years. Int J Primatol, 2002, 23: 1227-1244

4 Ying J S. Aregraphy of the endemic genera of seed plants in China. Acta Phyto Taxon Sin, 1996, 34: 479-485

5 Liu F, Chen W, He J. Population structure and regeneration of Quercusaliena var Acuteserrata in Shennongjia. Acta Phytoecol Sin, 2000, 24: 396-401

6 Xie Z. Characteristic and conservation priority of threatened plants in the Yangtze valley. Biodivers Conserv, 2003, 12: 65-72

7 Chen Z G, Yang J Y, Xie Z Q. Economic development of local 
communities and biodiversity conservation: A case study from Shennongjia National Nature Reserve, China. Biodivers Conserv, 2005, 14: 2095-2108

8 Zar J H. Biostatistical Analysis, 4th ed. Upper Saddle River, New Jersey: Prentice-hall Inc. Simon \& Schuster/A Viacom Company, 1999

9 Goodwin H J, Leader-Williams N. Protected area tourism-distorting conservation prioritie towards charismatic megafauna? In: Entwistle A, Dunstone N, eds. Priorities for the Conservation of Mammalian Diversity: Has the Panda Had Its Day? Cambridge: Cambridge University Press, 2000. 257-275

10 Fowler G. Behavioral and hormonal responses of Magellanic penguins (Spheniscus magellanicus) to tourism and nest site visitation. Biol Conserv, 1999, 90: 143-149

11 Walker B, Boersma P, Wingfield J. Habituation of adult magellanic penguins to human visitation as expressed through behavior and corticosterone secretion. Conserv Biol, 2006, 20: 146-154

12 Remis M. Prelminary assessment of the impacts of human activities on gorillas Gorilla gorilla and other wildlife at Dzanga-Sangha Reserve, Central African Republic. Oryx, 2000, 34: 56-65

13 Muyambi F. The impact of tourism on the behaviour of mountain gorillas. Gorilla J, 2005, 30: 14-15

14 Walpole M, Leader-Williams N. Masai Mara tourism reveals partnership benefits. Nature, 2001, 413: 771

15 Nevin O, Gilbert B. Perceived risk, displacement and refuging in brown bears: Positive impacts of ecotourism? Biol Conserv, 2005, 121: 611-622

16 Berger J. Population constraints associated with the use of black rhinos as an umbrella species for desert herbivores. Conserv Biol, 1997, 11: 69-78

17 Simberloff D. Flagships, umbrellas and keystones: Is single-species management passé in the land scapeera? Biol Conserv, 1998, 83: 247-257

18 Hunter C, Green H. Tourism and the Environment: A Sustainable Relationship? London: Routledge, 1995

19 Cole D. Trampling Effects on Mountain Vegetation in Washington, Colorado, New Hampshire and North Carolina, in Research Paper INT 464. Washington: Department of Agriculture, 1993

20 Sun D, Liddle M. A survey of trampling effects on vegetation and soil in eight tropical and subtropical sites. Environ Manage, 1993, 17: 497-510

21 Obua J. The potential, development and ecological impact of eco- tourism in Kibale National Park, Uganda. J Environ Manage, 1997, 50: $27-38$

22 Ikeda $\mathrm{H}$. Testing the intermediate disturbance hypothesis on species diversity in herbaceous plant communities along a human trampling gradient using a 4-year experiment in an old-field. Ecol Res, 2003, 18: 185-197

23 Brown K, Turner R, Hameed H, et al. Environmental carrying capacity and tourism development in the Maldives and Nepal. Environ Conserv, 1997, 24: 316-325

24 Walpole M, Karanja G, Sitati N, et al. Wildlife and People: Conflict and Conservation in Masai Mara, Kenya. London: IIED Wildlife and Development Series, IIED, 2003

25 Lafferty K, Gerber L. Good medicine for conservation biology: The intersection of epidemiology and conservation theory. Conserv Biol, 2002, 16: 593-604

26 Johns B. Responses of chimpanzees to habituation and tourism in the Kibale forest, Uganda. Biol Conserv, 1996, 78: 257-262

27 Butynski T, Kalina J. Gorilla tourism: A critical look. In: MilnerGulland E, Mace R, eds. Conservation of Biological Resources. Oxford: Blackwell Science, 1998. 280-300

28 Woodford M, Butynski T, Karesh W. Habituating the great apes: The disease risks. Oryx, 2002, 36: 153-160

29 Goldsmith M. Impacts of habituation for ecotourism on the gorillas of Nkuringo. Gorilla J, 2005, 30: 11-13

30 Macfie E J, Williamson E A. Best Practice Guidelines for Great Ape Tourism. Switzerland: The IUCN Species Survival Commission, 2007

31 Dunstone N, O'Sullivan J. The impact of ecotourism development on rainforest mammals. In: Taylor V, Dunstone N, eds. The Exploitation of Mammal Populations. London: Chapman and Hall, 1994. 313-333

32 Klein M, Humphrey S, Percival H. Effects of Ecotourism on Distribution of Waterbirds in a Wildlife Refuge. Conserv Biol, 1995, 9: 1454-1465

33 de la Torre S, Snowdon C, Bejarano M. Effects of human activities on wild pygmy marmosets in Ecuadorian Amazonia. Biol Conserv, 2000, 94: 153-163

34 Boyd S, Butler R. Managing ecotourism: An opportunity spectrum approach. Tourism Manage, 1996, 17: 557-566

35 Mullner A, Linsenmair K, Wikelski M. Exposure to ecotourism reduces survival and affects stress response in hoatzin chicks (Opisthocomus hoazin). Biol Conserv, 2004, 118: 549-558

Open Access This article is distributed under the terms of the Creative Commons Attribution License which permits any use, distribution, and reproduction in any medium, provided the original author(s) and source are credited. 